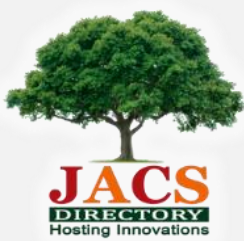

Journal of Nanoscience and Technology

\title{
Optical Properties of Aluminium Oxide Nanoparticles Synthesized by Leaf Extract of
}

\section{Ocimum sanctum}

\author{
Preeti Sharma ${ }^{1, *}$, Neera Sharma ${ }^{1}$, Nidhi $^{2}$, Neelam$^{3}$ \\ ${ }^{1}$ Department of Physics, Agra College, Agra - 282002, Uttar Pradesh, India. \\ 2Department of Physics, IBS Khandari, Agra - 282002, Uttar Pradesh, India. \\ ${ }^{3}$ Department of Chemistry, IBS Khandari, Agra - 282002, Uttar Pradesh, India.
}

\section{A R T I C L E D E T A I L S}

\section{Article history:}

Received 23 May 2019

Accepted 11 June 2019

Available online 13 June 2019

\section{Keywords:}

Aluminium Oxide

Green Synthesis

Optical Properties

\begin{abstract}
A B S T R A C T
In the present work aluminium oxide nanoparticles are synthesized using leaf extract of Ocimum sanctum. The synthesized sample was characterized by XRD, HR - TEM, UV - Vis, FTIR and PL. It is found that aluminium oxide nanoparticles synthesized by leaf extract are stable and show good optical properties. This method of synthesis is less toxic and cost of synthesis is low as compared to other chemical and physical methods. By XRD pattern phase of synthesized aluminium oxide nanoparticles is confirmed and the average particle size is found to be $19.43 \mathrm{~nm}$. By HR - TEM analysis, the particle size of synthesized nanoparticles ranges from $18 \mathrm{~nm}$ to $25 \mathrm{~nm}$. By UV - visible spectroscopy the energy band gap is found to be $2.55 \mathrm{eV}$. By FTIR analysis presence of Al-O band and biofunctional group is confirmed. Photoluminescence spectroscopy confirmed the energy band gap of as synthesized alumina nanoparticles is $2.19 \mathrm{eV}$. Hence, from the present study, it is concluded that aluminium oxide nanoparticles synthesized by plant leaf extract are good semiconductors.
\end{abstract}

\section{Introduction}

Nanoparticles are of great interest of research in every field due to their very large surface to volume ratio. Aluminium oxide is a compound of Aluminium and oxygen having chemical formula $\mathrm{Al}_{2} \mathrm{O}_{3}$. It is generally known as alumina. It is very hard, chemically inert, has high melting point, non- volatile and it has resistance to oxidation and corrosion [1-5]. There are many physical and chemical methods for the synthesis of Aluminium oxide nanoparticles some of which are ball milling, spray combustion, hydrothermal, sputtering, sol-gel, microwave and laser ablation [5-11].

The nanoparticles of aluminium oxide can be widely used in every field of science and engineering because of their interesting properties such as high stability, hardness, insulation, tunable mechanical properties etc. [6]. These nanoparticles can be used in the form of powder, fluid, films etc. These nanoparticles can be used in the treatment of waste water [9], as organic light emitting devices (OLEDs), solar selective coatings, bar code readers, optical lenses and windows [10].

In the present work aluminium oxide nanoparticles are synthesized using leaf extract of Ocimum sanctum and characterized by XRD, HR - TEM, UV - Vis, FTIR and PL.

\section{Experimental Methods}

\subsection{Synthesis of Aluminum Oxide Nanoparticles}

Plant extract was prepared using leaves of Ocimum sanctum (Tulsi). The leaves were first washed with tap water and then with distilled water to remove all the dust and unwanted particles. Then leaves were dried at room temperature. Now, Tulsi leaves are boiled in distilled water at $50{ }^{\circ} \mathrm{C}$ for about $12 \mathrm{~min}$. The solution is filtered using filter paper and a paleyellow clear solution is obtained and stored at about $4{ }^{\circ} \mathrm{C}$. Then, $2 \mathrm{mM}$ solution of aluminium nitrate was prepared by dissolving $\mathrm{AlNO}_{3}$ in distilled water. Tulsi abstract was mixed with this solution and it was kept under constant stirring using a magnetic stirrer for one and half hour. The change in colour from pale yellow to colloidal white indicated the formation of Aluminium oxide nanoparticles.

\subsection{Characterization Studies}

The crystalline size, structure, functional groups and energy band gap of sample are determined by XRD analysis, TEM, FTIR analysis, UV - Vis spectroscopy and PL. The XRD analysis was carried out on XPERT - PRO diffractometer operated at voltage $45 \mathrm{KV}$ and current $40 \mathrm{~mA}$. The HR TEM studies were carried out on model FP 5022/22 - Tecnai G2 20 S Twin. The FTIR analysis is carried out on PerkinElmer Spectrum Version 10.4 .00 in the wavelength range $400-4000 \mathrm{~cm}^{-1}$. The UV - Vis analysis is carried out on LAMBDA 1050 spectrometer in the wavelength range 200 - $800 \mathrm{~nm}$. Photoluminescence spectroscopy is carried out using $325 \mathrm{~nm}$ laser in wavelength range $335-807 \mathrm{~nm}$.

\section{Results and Discussion}

XRD diffraction studies are used to determine particle size and crystallinity of sample. The crystallite size is measured using Debey Scherrer's formula, $D=0.94 \lambda / \beta \cos \theta$, where $\lambda$ is the wavelength of $X$ - rays used which is $\mathrm{CuK}_{\alpha}$ radiation and $\beta$ is full width at half maximum of the diffraction peak corresponding to $2 \theta$. The wavelength of $\mathrm{CuK}_{\alpha}$ radiartion used is $1.54060 \AA$. Fig. 1 XRD patten of aluminium oxide nanoparticles. The average particle size of the nanoparticles calculated by above formula comes out to be $19.43 \mathrm{~nm}$.

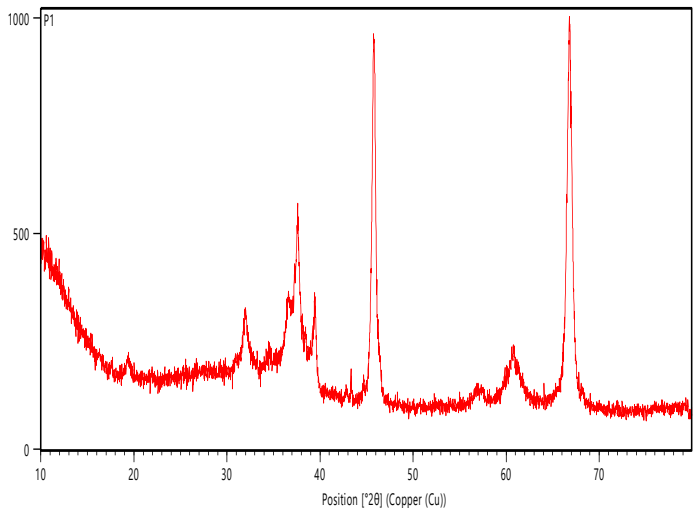

Fig. 1 XRD patten of aluminium oxide nanoparticles 
The TEM images of aluminium oxide nanoparticles (Fig. 2) revealed that the nanoparticles are nearly spherical in shape and their size ranging from $18 \mathrm{~nm}$ to $25 \mathrm{~nm}$.

FTIR spectrum is a useful tool to determine functional groups of the synthesized nanoparticles. The Fig. 3 shows characteristic peaks. The peaks at 796.85, 729.65 and $523.74 \mathrm{~cm}^{-1}$ are alumina peaks [12] which confirms formation of $\mathrm{Al}_{2} \mathrm{O}_{3}$ nanoparticles. Two peaks at 3458.58 and $3013.56 \mathrm{~cm}^{-1}$ are due to $-\mathrm{OH}$ stretching mode [13].

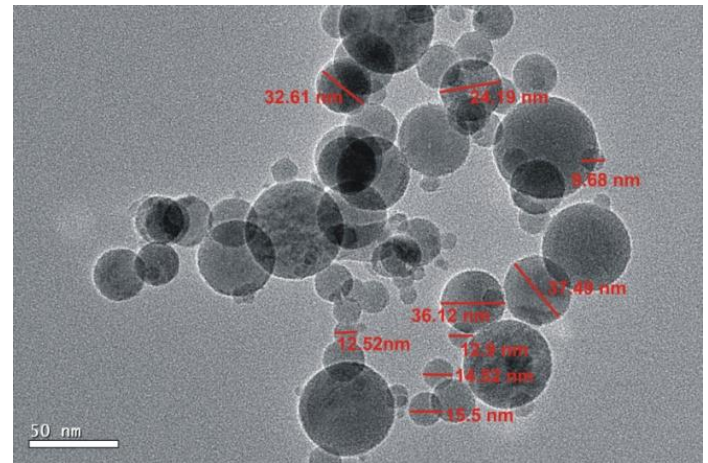

Fig. 2 TEM images of Aluminium oxide nanoparticles

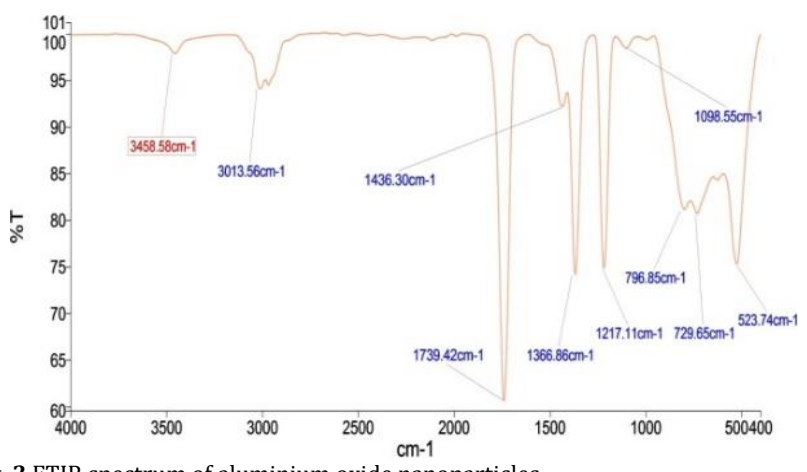

Fig. 3 FTIR spectrum of aluminium oxide nanoparticles

The UV-Vis spectrum is used to study optical properties of the sample. Light is passed though the sample solution and absorbed light is measured. The absorbance is measured by varying wavelength of light and graph is plotted between absorbance and wavelength of light which is shown in Fig. 4. The sample shows a strong absorption peak $\left(\lambda_{\max }\right)$ at $230 \mathrm{~nm}$ in the UV region. This is associated with photo excitation of electrons from valence band to conduction band.

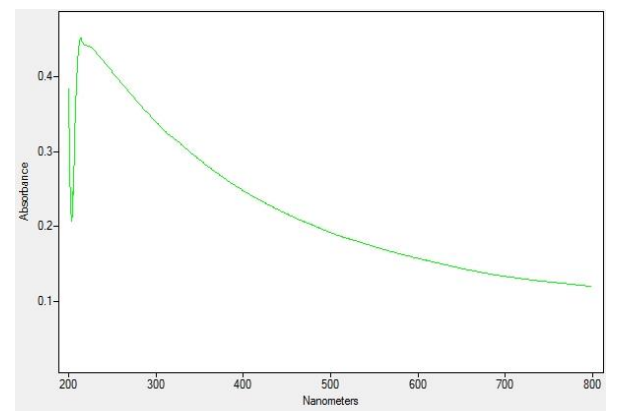

Fig. 4 UV-Vis absorption spectrum of aluminium oxide nanoparticles

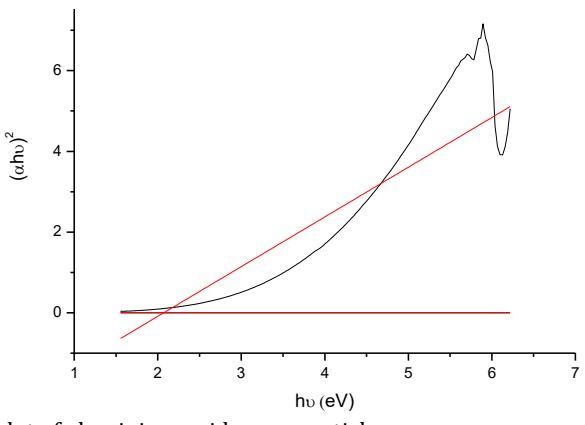

Fig. 5 Tauc's plot of aluminium oxide nanoparticles

The optical band gap of the aluminum oxide nanoparticles is calculated by Tauc's relation. A graph is plotted between $(\alpha h v)^{2}$ and hv. This is shown https://doi.org/10.30799/jnst.273.19050419 in Fig. 5. Here, $\alpha$ is absorbance, $h$ is Planck's constant and $v$ is the frequency of light. Intercept of straight line at $\alpha=0$ gives the value of optical band gap, which is $2.55 \mathrm{eV}$. This band gap is approximately equal to the band gap [14].

The PL spectrum of the sample is shown in Fig. 6 which shows a broad emission peak in the range $445-625 \mathrm{~nm}$. The broad emission peak is due to oxygen vacancies with three electrons [15]. The optical band gap of the sample can be calculated by peak position of the first peak of PL spectrum. For this sample, it is $2.19 \mathrm{eV}$, which is approximately equal to the optical band gap calculated by UV-Vis spectrum of the same sample. From PL spectrum it is also clear that there is good emission in green - yellow region.

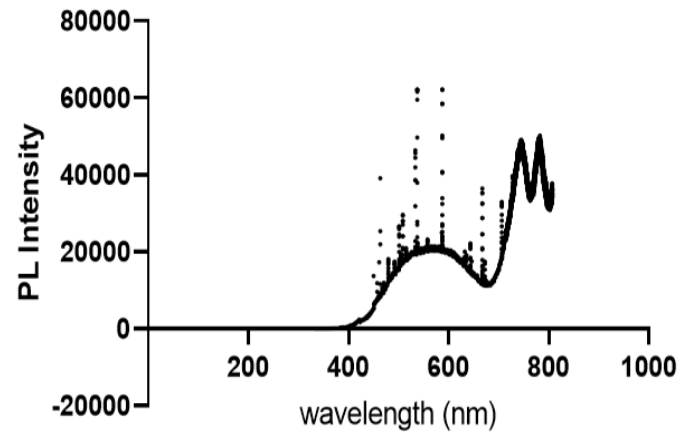

Fig. 6 PL spectrum of aluminium oxide nanoparticles

\section{Conclusion}

From this work, it is concluded that aluminium oxide nanoparticles are successfully synthesized using leaf extract of Ocimum sanctum. XRD analysis revealed that the particle size is in nanometer range which comes out to be $19.43 \mathrm{~nm}$. This is in agreement with the particles size shown in $\mathrm{HR}$ - TEM images. FTIR analysis confirms the presence of $\mathrm{Al}-\mathrm{O}$ functional group. UV - Vis spectroscopy confirms the formation of $\mathrm{Al}_{2} \mathrm{O}_{3}$ nanoparticles. PL suggests that the sample is extremely pure. The energy band gap of these nanoparticles suggests that these are very good semiconductors. PL study revealed that there is good emission in green yellow region so these nanoparticles can be used as LEDs of green - yellow colour.

\section{Acknowledgement}

Authors are thankful to Head, Department of Physics and Head, Department of Chemistry of Agra College, Agra for providing necessary facilities regarding experimental work. The authors would like to thank SAIF, Punjab University, Chandigarh for XRD; MRC, MNIT, Jaipur for UV Vis, FTIR and PL; and AMRC, IIT Mandi for TEM analysis.

\section{References}

[1] S. Iravani, Green synthesis of metal nanoparticles using plants, Green Chem. 13(10) (2011) 2638-2650.

[2] K.S. Kavitha, B. Syed, D. Rakshith, H.U. Kavitha., R.H.C. Yashwantha, et al., Plants as green source towards synthesis of nanoparticles, Int. Res. J. Bio. Sci. 2(6) (2013) 66-76.

[3] V. Vadlapudi, K. Kaladhar, M. Behara, B. Sujatha, G.K. Naidu, Synthesis of green metallic nanoparticles (NPs) and applications, Open J. Chem. 29(4) (2014) 1589-1595.

[4] P. Malik, R. Shankar, V. Malik, N. Sharma, T.K. Mukherjee, Green chemistry based benign routes for nanoparticle synthesis, J. Nanoparticle Res. 2014 (2014) 302429:1-14

[5] A.H. Tavakoli, P. Saradhi Maram, S.J. Widgeon, J. Rufner, K. Van Benthem, et al., Amorphous alumina nanoparticles: Structure, surface energy, and thermodynamic phase stability, Phys. Chem. C 117(33) (2013) 17123-17130.

[6] Y.K. Park, E.H. Tadd, M. Zubris, R. Tannenbaum, Size-controlled synthesis of alumina nanoparticles from aluminum alkoxides, Mater. Res. Bull. 40(9) (2005) 1506-1512.

[7] R. Rogojan, E. Andronescu, C. Ghitulica, B.S. Vasile, Synthesis and characterization of alumina nanopowder obtained by sol-gel method, U.P.B. Sci. Bull. 73 (2011) 67-76.

[8] S.M. Metev, V.P. Veiko, Laser assisted microtechnology, $2^{\text {nd }}$ Edn., SpringerVerlag, Germany, 1998.

[9] J. Breckling, The analysis of directional time series: Applications to wind speed and direction, Series Lecture Notes in Statistics, Vol. 61, Springer, Berlin Germany, 1989.

[10] M. Lebedev, S. Krumdieck, Optically transparent, dense a- $\mathrm{Al}_{2} \mathrm{O}_{3}$ thick films deposited on glass at room temperature, Curr. Appl. Phys. 8 (2008) 233-236.

[11] S. Zhang, C. Zhu, J.K.O. Sin, P.K.T. Mok, A novel ultrathin elevated channel lowtemperature poly-Si TFT, IEEE Electron Device Lett. 20 (1999) 569-571. 
[12] T. Zaki, K.L. Kabel, H. Hassan, Preparation of high pressure pure $\alpha-\mathrm{Al}_{2} \mathrm{O}_{3}$ nanoparticles at room temperature using Pechini method, Cream Int. 38(3) (2012) 2021-2026

[13] Z Guo, T. Pereira, O. Choi, Y. Wang, H.T. Hahn, Surface functionalized alumina nanoparticle filled polymeric nanocomposites with enhanced mechanical properties, J. Mater. Chem. 16(27) (2006) 2800-2808.
[14] P. Duraisamy, Green synthesis of aluminium oxide nanoparticles by using Aerva lanta and Terminalia chebula extracts, Int. J. Res. Appl. Sci. Eng. Tech. 6(I) (2018) 428-433.

[15] P.A. Prashantha, R.S. Raveendra, R. Hari Krishna, S. Ananda, N.P. Bhagya, et al Synthesis, characterizations, antibacterial and photoluminescence studies of solution combustion-derived - $\mathrm{Al}_{2} \mathrm{O}_{3}$ nanoparticles, J. Asian Ceram. Soc. 3 (2015) 345-351. 